\title{
Learning process of ultrasound-guided llio- fascial compartment block on a simulator: a feasibility study
}

Julien Celi ${ }^{1 *}$, Christophe A. Fehlmann ${ }^{1}$, Olivier T. Rutschmann¹, Iris Pelieu-Lamps², Roxane Fournier², Mathieu Nendaz ${ }^{3}$, François Sarasin ${ }^{1}$ and Frédéric Rouyer ${ }^{1}$

\begin{abstract}
Background: Ultrasound-guided fascia iliaca compartment block (US-FICB) is not part of the learning curriculum of the emergency physicians (EP) and is usually performed by anesthesiologists. However, several studies promote EP to use this procedure.

The goal of this study was to assess the feasibility of a training concept for non-anesthesiologists for the US-FICB on a simulator based on a validating learning path.

Method: This was a feasibility study. Emergency physicians and medical students received a 1-day training with a learning phase (theoretical and practical skills), followed by an assessment phase.

The primary outcome at the assessment phase was the number of attempts before successfully completing the procedure. The secondary outcomes were the success rate at first attempt, the length of procedure (LOP), and the stability of the probe, corresponding to the visualization of the needle tip (and its tracking) throughout the procedure, evaluated on a Likert scale.

Results: A total of 25 participants were included. The median number of attempts was 2.0 for emergency physicians and 2.5 for medical students, and this difference was not significant ( $p=0.140$ ). Seven participants (28\%) succeeded at the first attempt of the procedure; the difference between emergency physicians and medical students was not significant (37\% versus 21\%; $p=0.409$ ). The average LOP was 19.7 min with a significant difference between emergency physicians and medical students $(p=0.001)$. There was no significant difference regarding the stability of the probe between the two groups.
\end{abstract}

Conclusion: Our 1-day training for non-anesthesiologists with or without previous skills in ultrasound seems to be feasible for learning the US-FICB procedure on a simulator.

Keywords: Ultrasound-guided fascia iliaca bock, Learning process, Emergency physician

\footnotetext{
* Correspondence: julien.celi@hcuge.ch

${ }^{1}$ Emergency Unit, Department of Acute Medicine, Geneva University Hospitals, Rue Gabrielle-Perret-Gentil 2, CH-1205 Geneva, Switzerland

Full list of author information is available at the end of the article
}

(c) The Author(s). 2020 Open Access This article is licensed under a Creative Commons Attribution 4.0 International License, which permits use, sharing, adaptation, distribution and reproduction in any medium or format, as long as you give appropriate credit to the original author(s) and the source, provide a link to the Creative Commons licence, and indicate if changes were made. The images or other third party material in this article are included in the article's Creative Commons licence, unless indicated otherwise in a credit line to the material. If material is not included in the article's Creative Commons licence and your intended use is not permitted by statutory regulation or exceeds the permitted use, you will need to obtain permission directly from the copyright holder. To view a copy of this licence, visit http://creativecommons.org/licenses/by/4.0/ The Creative Commons Public Domain Dedication waiver (http://creativecommons.org/publicdomain/zero/1.0/) applies to the data made available in this article, unless otherwise stated in a credit line to the data. 


\section{Introduction}

Hip fracture is a common pathology in Emergency Departments (ED) and most often involves polymedicated elderly patients with frequent severe co-morbidities [1], https://www.obsan.admin.ch/fr/indicateurs/taux-dhospitalisation-pour-fracture-de-la-hanche.

Despite the fact that effective pain relief is a major challenge in this process, patients are at high risk for not receiving adequate analgesia in a crowded ED [2, 3], especially if they suffer from cognitive disorders $[4,5]$.

In response to suboptimal pain management that results in oligoanalgesia, various strategies have been developed to improve this situation, some beginning at the ED door, e.g., implementation of a medico-delegated analgesia protocol, campaigns on pain management, fasttrack management, and strategies for shortening the time to intervention. Opiate treatment is frequent in the acute phase. Therapeutic equilibrium is not obvious to achieve, which can result in risk of under dosage for fear, secondary effects (delirium, fall, urinary globe), and potential respiratory repercussions. Regional analgesia is a widely recognized analgesia technique for pain analgesia. FICB is a compartmental block allowing excellent analgesia of the proximal part of the femur [6]. Historically performed "blindly" using anatomical landmarks, USFICB has become a standard $[7,8]$. This technique, which is usually performed by anesthesiologists, can be performed by emergency physicians, nurses, and paramedics with relatively little experience $[9,10]$. However, there is currently no structured and evidence-based training program for this procedure.

The aim of this project was to assess the feasibility and the effect of a training concept for non-anesthesiologists with or without prior ultrasound skills in the acquisition of technical skills for ultrasound-guided regional anesthesia (UGRA) using a high-fidelity simulator to learn US-FICB.

\section{Method and materials \\ Design and setting}

This was a monocentric pilot study in the ED of a primary and tertiary urban teaching hospital in Geneva, Switzerland, that admits 73,000 patients per year.

\section{Study population}

Participants were enrolled on a voluntary basis. Inclusion criteria depended on the profile of the participants. Enrolled emergency physicians had a full position in an emergency division, at least 5 years of postgraduate training, and daily experience in point-of-care ultrasound (group with previous experience in US but not in US-guided regional anesthesia). Enrolled medical students were in their third year of a 6-year medical school program and had not taken, except theoretical lessons, a practical ultrasound course or used an ultrasound machine before (group without previous experience in US).

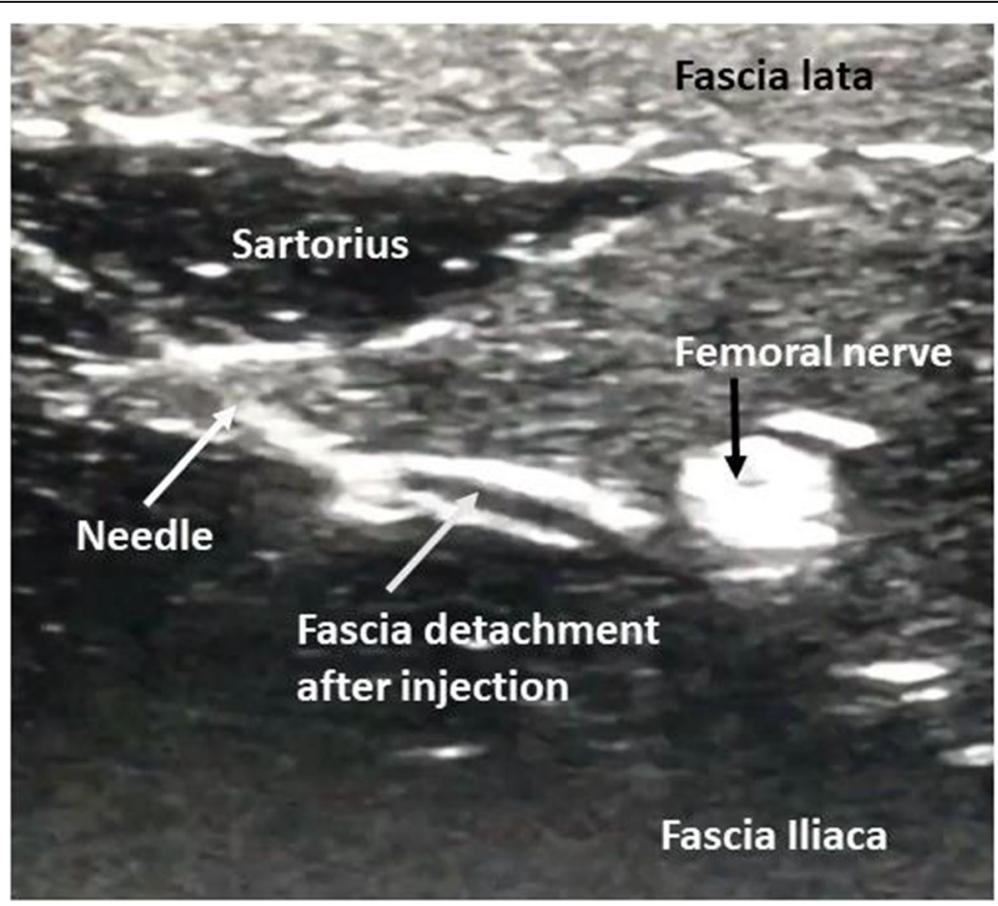

Fig. 1 Sono-anatomical landmarks for the simulator/target injection 


\section{Materials}

The high-fidelity simulator used in this study was a Nysora MS2-FEM. This simulator allows hydro dissection and injection under ultrasound control, increasing the level of realism with a high degree of fidelity (Fig. 1). The real-life FICB procedure usually consists of administering $30-40 \mathrm{ml}$ of local anesthetic divided into two syringes. Due to limitations in volume injection on the simulator, it was decided that, for the study, $2 \times 5 \mathrm{ml}$ of saline serum would be injected to simulate the handling and changing of syringes. Syringes used were Stimuplex ${ }^{\odot}$ Ultra $360^{\circ} 22 \mathrm{Ga}$ (B. Braun Melsungen AG). Linear array ultrasound probes (L12-4 for Philips-SPARQ ${ }^{\circ}$ and HFL38x for SonoSite, Inc.) were used.

\section{Teaching session}

Four sessions were organized, each with six to eight participants. Each session was under the direct supervision of two instructors, either two attending emergency physicians or one attending emergency physician and one anesthesiologist physician.

A station checklist (Fig. 2) was consensually established by the expert group, which included two senior

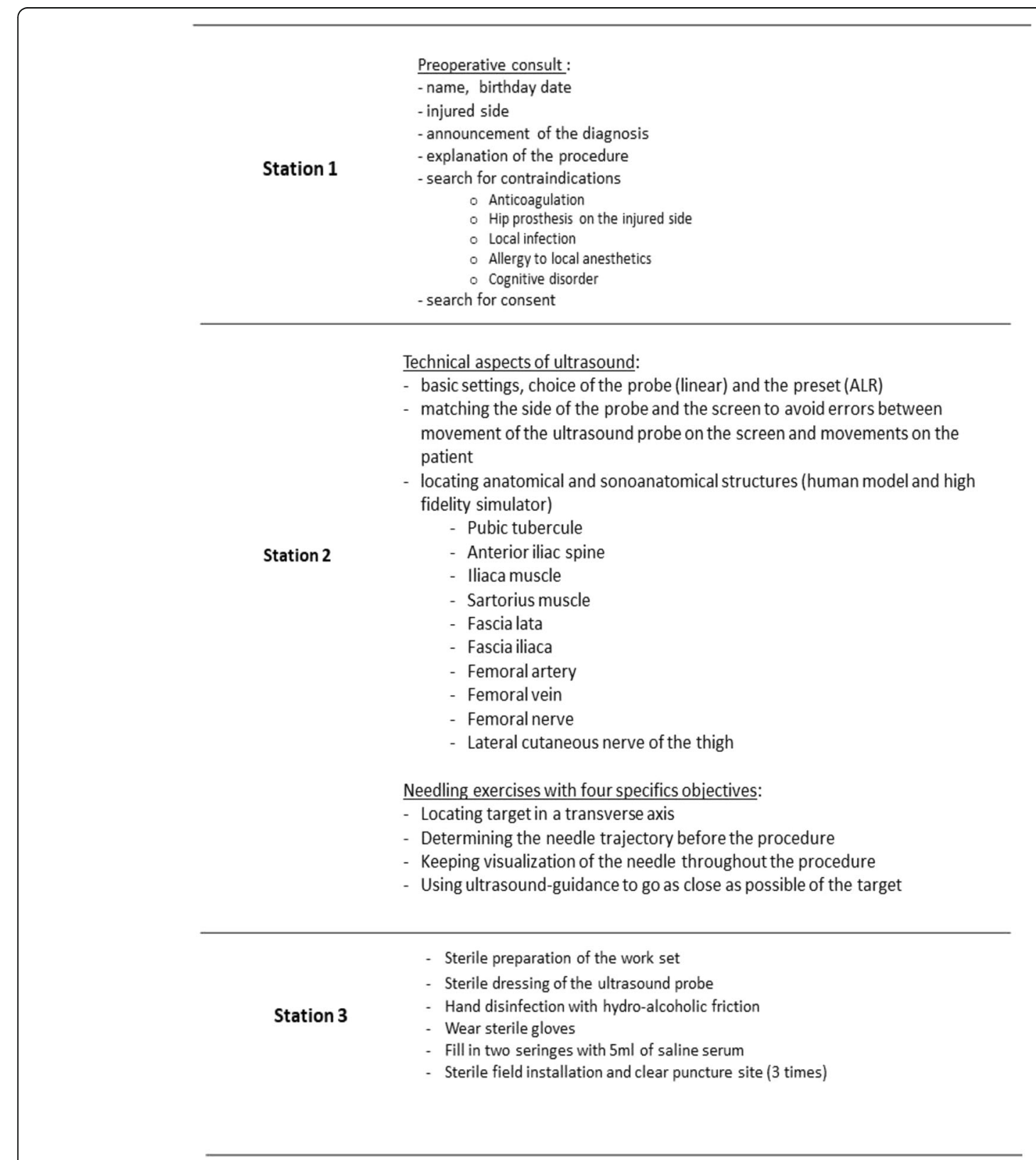

Fig. 2 Formative station checklist 
anesthesiologists, who are experts in UGRA (RF, IP), and two senior emergency physicians (FR, JC).

The teaching session consisted of three parts: one 1-h theoretical session, three 1-h supervised practical sessions, and the viewing of an institutional video showing "the perfect procedure: US-FICB on a high-fidelity simulator." The participant-to-instructor ratio was 3:1 or 4:1 for practical sessions.

\section{Assessment session}

In the afternoon after training, each participant underwent an individual, timed evaluation on the simulator the participant used previously. Except for one session with only one expert (JC), all the individual assessment sessions were under the supervision of two experts (the same as in the teaching session). JC was present for all sessions. The assessment checklist included 5 steps with a total of 16 control items (Table 1) and was developed by the same expert group that developed the station checklist.

Participants had to perform steps 1-3 chronologically to continue the procedure. In case of error, the experts could interrupt the participant to provide verbal feedback, after which the participant had to repeat all the items of the steps that had been performed in error.
The points noted with an asterisk in Table 1 are those identified as critical as they can cause the needle to exit the skin to create a new puncture. Stability of the probe, the only item for which feedback was not given during the evaluation, was evaluated separately by the two experts at the end of the procedure. After comparing their own assessment, which was scored on a 5-level Likert scale from -2 (low stability) to +2 (high stability), a consensus was easily found.

Participants had to complete all the items to pass the evaluation (sufficient US-FICB skill acquired). They could not ask the instructor questions except for technical issues. Number of skin breakthroughs was recorded by one of the reviewers. No physical feedback (taking control of the needle) was given.

\section{Outcomes measure}

The primary outcome at the assessment phase after the training was the number of attempts before successfully completing the procedure. An attempt was defined as a skin breakthrough. Success was defined as the completion of every point of the checklist (Table 1) in less than $45 \mathrm{~min}$. Secondary outcomes were successful at first attempt, length of procedure (LOP), and stability of the probe. LOP was defined as the time needed to accomplish the 16 prespecified items listed in Table 2. The

Table 1 Assessment checklist

\begin{tabular}{|c|c|c|c|}
\hline Boxes & Steps & Acquired & $\begin{array}{l}\text { Not } \\
\text { acquired }\end{array}$ \\
\hline \multirow[t]{2}{*}{ 1. Preoperative consult } & Knowledge and compliance for contraindications & & \\
\hline & Explanation of the procedure and obtaining consent & & \\
\hline \multirow[t]{2}{*}{ 2. Technical aspects } & Choice of ultrasound probe & & \\
\hline & Correct preset selection (loco-regional anesthesia) & & \\
\hline \multirow[t]{5}{*}{ 3. Asepsis } & Physician's clothing & & \\
\hline & Preparation of syringes $(2 \times 5 \mathrm{ml}$ saline serum $)$ & & \\
\hline & Preparation of the probe & & \\
\hline & Correct cleaning of the site & & \\
\hline & Sterile gel for the puncture area & & \\
\hline \multirow{4}{*}{$\begin{array}{l}\text { 4. Ultrasound guidance and anatomical } \\
\text { identification }\end{array}$} & Correct orientation of the probe & & \\
\hline & ${ }^{*}$ Anatomical and sono-anatomical landmarks & & \\
\hline & *Ideal trajectory and in-plane progression & & \\
\hline & $\begin{array}{l}\text { Stability of the probe throughout the procedure* } \\
*_{-}^{*}=\text { low stability } /+2 \text { high stability }\end{array}$ & $-2,-1,0$ & $+1,+2$ \\
\hline \multirow[t]{3}{*}{ 5. Hydro-dissection procedure } & Visualization of the needle tip throughout the procedure & & \\
\hline & Suction before injection & & \\
\hline & $\begin{array}{l}\text { *Identification of the injection area, injection of } 2 \times 5 \mathrm{cc} \text { (syringe change), } \\
\text { and visualization of fascia detachment }\end{array}$ & & \\
\hline \multicolumn{4}{|l|}{ Ultrasound-guided FICB } \\
\hline \multicolumn{4}{|l|}{ Number of breakthroughs } \\
\hline LOP & & & \\
\hline
\end{tabular}


Table 2 Participant characteristics

\begin{tabular}{lll}
\hline Level of expertise & Medical students $(\boldsymbol{n}=\mathbf{1 4})$ & Emergency physicians $(\boldsymbol{n}=\mathbf{1 1})$ \\
\hline Age $^{a}$, years & $24 \pm 1$ & $34 \pm 2$ \\
Females, number (\%) & $5(36)$ & $4(36)$ \\
Postgraduate experience ${ }^{a}$, year & NA & $7 \pm 2$ \\
\hline
\end{tabular}

${ }^{a}$ Means \pm SD

stability of the probe was evaluated by the two observers and scored on a scale from -2 (low stability) to +2 (high stability). Based on the maximum acceptable duration of a procedure, a procedure longer than $45 \mathrm{~min}$ was considered as failed.

\section{Statistical analysis}

Mann-Whitney-Wilcoxon test and Fischer's exact test were used for comparisons between groups. For all tests, a two-sided $P$ value less than 0.05 was considered significant. Statistical analyses were performed using STATA version 14 (Stata Corporation, TX, USA).

\section{Results}

Twenty-five participants were included: 11 senior emergency physicians and 14 medical students, $64 \%$ of whom were male. Participant characteristics are presented in Table 2. All participants were right handed and finished the procedure.

Outcome results are shown in Fig. 3 and Table 3.

For the primary outcome, the median number of attempts was $2.0 \quad(95 \%$ CI $1.0-2.9)$ for emergency physicians and 2.5 (95\% CI 2.0-3.0) for medical students, and the difference between the groups was not statistically significant $(p=0.140)$.

For the secondary outcome, the first attempts of seven participants $(28 \%)$ were successful, and there was a clinically significant difference between emergency physicians and medical students (37\% versus $21 \% ; p=0.409$ ).

The average LOP was $19.7 \mathrm{~min}$, with a significantly shorter LOP for emergency physicians (15.3 min, 95\% CI 13.4-17.2, versus $23.2 \mathrm{~min}$, 95\% CI 19.626.8, $p=0.001$ ).

Finally, the overall average stability of the probe was 0.9 , with no significant difference between emergency physicians and medical students ( 1.5 versus 0.5 , $p=0.215$ ).

No vascular or nervous puncture was performed.

\section{Discussion}

This study demonstrates that a 1-day structured, competence-based training seems sufficient for learning US-FICB with a simulator regardless of previous experience in US.

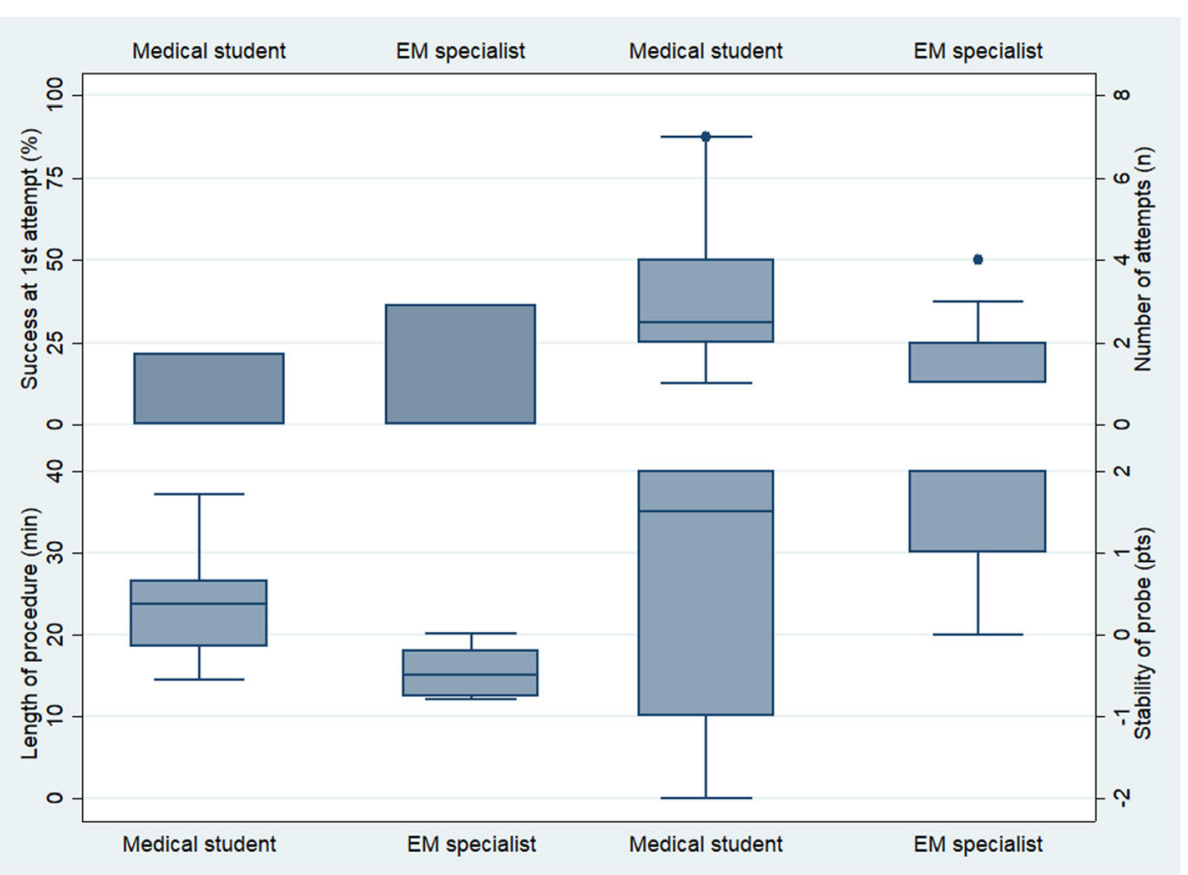

Fig. 3 Primary and secondary outcomes at the end of training 
Table 3 Primary and secondary outcomes

\begin{tabular}{|c|c|c|c|}
\hline Level of expertise & Medical students $(n=14)$ & Emergency physicians $(n=11)$ & $p$ value \\
\hline Number of attempts $^{a}$ & $2.5[2.0-3.0]$ & $2.0[1.0-2.9]$ & 0.140 \\
\hline Success at first attempt, number (\%) & $3(21)$ & $4(37)$ & 0.409 \\
\hline Length of procedure ${ }^{\mathrm{b}}$, min & $23.2 \pm 6.2$ & $15.3 \pm 2.9$ & 0.001 \\
\hline Stability of probe ${ }^{b}$, points & $0.5 \pm 1.7$ & $1.5 \pm 0.8$ & 0.215 \\
\hline
\end{tabular}

${ }^{a}$ Median [95\% Cl]

${ }^{\mathrm{b}}$ Means $\pm \mathrm{SD}$

The use of locoregional anesthesia in acute pain management in the ED, particularly of FICB for fractures of the proximal femur, is well-established [11]. The FICB practice is effective and safe and can be performed by non-anesthesiologist [12, 13]. However, there are obstacles to transfer of competence, including the lack of training for emergency doctors in the performance of UGRA. However, this study indicates that providing sufficient training can easily be accomplished.

The observed difference in first attempt success rate between experienced practitioners and medical students, although not statistically significant, was $26 \%$ in favor of the experienced group. This is an important difference and the lack of statistical significance likely reflects that the study was seriously underpowered with respect to this outcome (see limitations). This difference can be explained by the previous experience of senior physician in US-guided procedures such as central line. As demonstrated in the study of Kim et al. [14], novice students in UGRA significantly improve their learning curve after five attempts for a simple nerve block (as the FICB) on a simulator; this observation reflects the learning curve of the students in our study (by adding up all the trainings of the day, the individual number of attempts exceeded five per participant). The median number of attempts in this study agrees well with those reported by Morse et al. [15] and Liu et al. [16]. The acquisition of simple technical skills (low difficulty block, as with the FICB) does not seem to require a strong medical background, and this is likely due to the focus in the training on the acquisition of a specific procedural skill.

The stability of the probe was not significantly different between the two groups, even though there was a clear trend that the stability achieved by the students was inferior to that by the physicians. As described by Sites et al. [17], poor stability is among the most frequent errors made by novices in the acquisition of an ultrasound-based gesture in locoregional anesthesia. Note that, during the evaluation session, the instructors provided oral feedback freely on the conduct and monitoring of the probe, particularly to students, and it would have been interesting to measure the impact of such feedback on the performance and reliability of the results obtained. Although it was not addressed in this study, it would be interesting to assess whether the hand-eye coordination obtained by habitual playing of video games influences the learning curve of trainees using the simulator [18].

The LOP required by students was significantly longer than for physicians. This can be explained by the prior experience of the emergency physicians for the preparation of the material, the disinfection of the patient, and the dressing of the probe-experience that the students had not yet gained. Observers had the impression that steps 1-3 (see Table 2) required considerably more time for students to complete. To ensure that the assessment provides realistic data for a competency-based curriculum, a total procedure time of maximum 45 min was chosen for this study.

The training curriculum developed in this study was based on the most recent evidence for technical learning in the medical field, on the contribution of simulation to learning UGRA and on expert recommendations in good practice of the FICB [19-23]. To our knowledge, this study is the first to compare the acquisition of skills by physicians and medical students for US-FICB using a simulator.

Some limitations should, however, be acknowledged. First, the most important limitation is the likely lack of statistical power of the study.

Secondly, the participants in each experience group were unbalanced in number and gender. Emergency physicians generally had a wide range of proficiency in US. With a larger number of participants, future studies should determine the skill level of physicians before training to meaningfully measure the impact of this program.

Thirdly, different co-examiners performed evaluation in the assessment sessions, potentially adding bias to the evaluations. This potential bias was limited as the main author acted as a co-examiner for all evaluations. Despite the fact that various studies have measured the positive impact of combining verbal and physical feedback on performance during skill learning [24], we chose to only give verbal feedback in this study. We did not measure the number of times feedback was given, although such data could be interesting with a larger number of participants. Although the impact of 
simulation in the transfer of skills learned in clinical practice is clearly appreciated for most teaching models and undeniably provides added value with respect to the perception of the learners, the real impact of simulation is yet to be determined $[19,25]$. Another limitation of this study could be the extrapolation of the results to clinical practice, as a single size of manikin was used and is not representative of all the actual sono-anatomical landmarks encountered in clinical practice. In addition, the assessment session took place on the same day as the teaching session, and, therefore, only the short-term effect of the training was evaluated. In future studies, a second assessment session 1 or 3 months later could be added to evaluate long-term effects, including a questionnaire evaluating the impact of the training in the implementation of the technique in the clinical practice of the physicians included in the study as well as their degree of satisfaction. Although the US-FICB is carried out autonomously by EPs in different countries, our EPs do not have the prerequisite to do so. We have therefore not been able to assess how many physicians have included this technique in their clinical practice or even assess the maintenance of competence. However, we hope that our study can be the starting point of the training for non-anesthesiologists in our hospital.

Finally, fatigability of participants, unmeasured in this study, could have influenced performance [18].

\section{Conclusion}

This study demonstrates the feasibility of a training concept for non-anesthesiologists with or without prior US skills for the performance of US-FICB on a high-fidelity simulator. More studies involving real patients and longterm effect are needed to evaluate transfer of competence.

\section{Acknowledgements}

Not applicable.

\section{Authors' contributions}

Conceptualization: J. Celi, O.T. Rutschmann, I. Pelieu, R. Fournier, M. Nendaz, F. Rouyer; data curation: C.A. Fehlmann; formal analysis: C.A. Fehlmann; funding acquisition: F. Sarasin; investigation: J. Celi, F. Rouyer; project administration: F. Sarasin, F. Rouyer; supervision: F. Sarasin, F. Rouyer; writing of original draft: J. Celi, C.A. Fehlmann; writing review and editing: J. Celi, O.T. Rutschmann, C.A. Fehlmann, R. Fournier, M. Nendaz, F. Sarasin, F. Rouyer. The authors read and approved the final manuscript.

\section{Funding}

No funding was obtained for this study.

\section{Availability of data and materials}

The data that support the findings of this study are publicly available upon request.

\section{Ethics approval and consent to participate}

The study was conducted at Geneva University Hospitals in accordance with Good Clinical Practice (Declaration of Helsinki 2002). After consultation with the institutional ethics committee (Geneva, Switzerland), a complete review of the study was waived.
Participants consent to participate was obtained.

Consent for publication

Not applicable

\section{Competing interests}

The authors declare that they have no competing interests.

\section{Author details}

${ }^{1}$ Emergency Unit, Department of Acute Medicine, Geneva University Hospitals, Rue Gabrielle-Perret-Gentil 2, CH-1205 Geneva, Switzerland. ${ }^{2}$ Anesthesiology Unit, Department of Acute Medicine, Geneva University Hospitals, Geneva, Switzerland. ${ }^{3}$ Unit of Development and Research in Medical Education, Faculty of Medicine, and Department of Medicine, Geneva University Hospitals, Geneva, Switzerland.

Received: 20 July 2020 Accepted: 16 November 2020

Published online: 30 November 2020

\section{References}

1. Lippuner K, Grifone S, Schwenkglenks M, et al. Comparative trends in hospitalizations for osteoporotic fractures and other frequent diseases between 2000 and 2008. Osteoporos Int. 2012;23(3):829-39. https://doi.org/ 10.1007/s00198-011-1660-8.

2. Gobet M, Rutschmann OT, Sarasin F, Villar A, Mugnier B RM. Oligoanalgesia in the emergency department waiting room: predictive factors. EUSEM XI Eur Congr Emerg Med Athens 2017. 2017.

3. Hwang U, Richardson L, Livote E, Harris B, Spencer N, Morrison RS. Emergency department crowding and decreased quality of pain care. Acad Emerg Med. 2008;15(12):1248-55. https://doi.org/10.1111/j.15532712.2008.00267.x.

4. Morrison RS, Siu AL. A comparison of pain and its treatment in advanced dementia and cognitively intact patients with hip fracture. J Pain Symptom Manag. 2000. https://doi.org/10.1016/S0885-3924(00)00113-5.

5. Markey G, Reilly N, Kelly P, Kelly C. Delayed emergency analgesia for patients with dementia and hip fracture. Geriatr Orthop Surg Rehabil. 2016. https://doi.org/10.1177/2151458516642581.

6. Swenson JD, Davis JJ, Stream JO, Crim JR, Burks RT, Greis PE. Local anesthetic injection deep to the fascia iliaca at the level of the inguinal ligament: the pattern of distribution and effects on the obturator nerve. J Clin Anesth. 2015. https://doi.org/10.1016/j.jclinane.2015.07.001.

7. Dolan J, Williams A, Murney E, Smith M, Kenny GNC. Ultrasound guided fascia iliaca block: a comparison with the loss of resistance technique. Reg Anesth Pain Med. 2008. https://doi.org/10.1016/j.rapm.2008.03.008.

8. Desmet M, Balocco AL, Van Belleghem V. Fascia iliaca compartment blocks: different techniques and review of the literature. Best Pract Res Clin Anaesthesiol. 2019;33(1):57-66. https://doi.org/10.1016/j.bpa.2019.03.004.

9. McRae PJ, Bendall JC, Madigan V, Middleton PM. Paramedic-performed fascia iliaca compartment block for femoral fractures: a controlled trial. J Emerg Med. 2015. https://doi.org/10.1016/j.jemermed.2014.12.016.

10. Scurrah A, Shiner CT, Stevens JA, Faux SG. Regional nerve blockade for early analgesic management of elderly patients with hip fracture - a narrative review. Anaesthesia. 2018. https://doi.org/10.1111/anae.14178.

11. Steenberg J, Møller AM. Systematic review of the effects of fascia iliaca compartment block on hip fracture patients before operation. $\mathrm{Br} J$ Anaesth. 2018. https://doi.org/10.1016/j.bja.2017.12.042.

12. Ketelaars R, Stollman JT, Van Eeten E, Eikendal T, Bruhn J, Van Geffen G-J. Emergency physician-performed ultrasound-guided nerve blocks in proximal femoral fractures provide safe and effective pain relief: a prospective observational study in The Netherlands. doi:https://doi.org/10. 1186/s12245-018-0173-Z.

13. M. Freyz, F. Adnet, Y. Auroy PG et al. Pratique des anesthesies locales et locorégionales par des médecins non spécialisés en anesthésie réanimation dans le cadre des urgences. Ann Fr Anesth Reanim. 2004.

14. Kim SC, Hauser S, Staniek A, Weber S. Learning curve of medical students in ultrasound-guided simulated nerve block. J Anesth. 2014. https://doi.org/10. 1007/s00540-013-1680-y.

15. Morse J, Terrasini N, Wehbe $M$, et al. Comparison of success rates, learning curves, and inter-subject performance variability of robot-assisted and manual ultrasound-guided nerve block needle guidance in simulation. $\mathrm{Br}$ J Anaesth. 2014;112(6):1092-7. https://doi.org/10.1093/bja/aet440. 
16. Liu Y, Glass NL, Glover CD, Power RW, Watcha MF. Comparison of the development of performance skills in ultrasound-guided regional anesthesia simulations with different phantom models. doi:https://doi.org/10.1097/SIH. 0b013e318299dae2.

17. Sites BD, Spence BC, Gallagher JD, Wiley CW, Bertrand ML, Blike GT. Characterizing novice behavior associated with learning ultrasound-guided peripheral regional anesthesia. Reg Anesth Pain Med. 2007. https://doi.org/ 10.1016/j.rapm.2006.11.006

18. Harbin AC, Nadhan $\mathrm{KS}$, Mooney JH, et al. Prior video game utilization is associated with improved performance on a robotic skills simulator. J Robot Surg. 2017;11(3):317-24. https://doi.org/10.1007/s11701-016-0657-x.

19. Cook DA, Hamstra SJ, Brydges R, et al. Comparative effectiveness of instructional design features in simulation-based education: systematic review and meta-analysis. Med Teach. 2013. https://doi.org/10.3109/ $0142159 X .2012 .714886$

20. Chen XX, Trivedi V, AlSaflan AA, et al. Ultrasound-guided regional anesthesia simulation training. Reg Anesth Pain Med. 2017. https://doi.org/10.1097/ AAP. 0000000000000639 .

21. Aggarwal R, Grantcharov TP, Darzi A. Framework for systematic training and assessment of technical skills. J Am Coll Surg. 2007. https://doi.org/10.1016/j. jamcollsurg.2007.01.016.

22. Kim TE, Tsui BCH. Simulation-based ultrasound-guided regional anesthesia curriculum for anesthesiology residents. Korean J Anesthesiol. 2019;72(1):1323. https://doi.org/10.4097/kja.d.18.00317.

23. Tan JS, Chin KJ, Chan WWS. Developing a training program for peripheral nerve blockade: the "nuts and bolts.". Int Anesthesiol Clin. 2010:48(4):1-11. https://doi.org/10.1097/AIA.0b013e3181f17a18.

24. Lerman IR, Souzdalnitski D, Halaszynski T, Dai F, Guirguis M, Narouze SN. Ultrasound-guided regional anesthesia simulation and trainee performance. Tech Reg Anesth Pain Manag. 2014. https://doi.org/10.1053/j.trap.2015.10.008.

25. Ziv A, Small SD, Wolpe PR. Patient safety and simulation-based medical education. Med Teach. 2000. https://doi.org/10.1080/01421590050110777.

\section{Publisher's Note}

Springer Nature remains neutral with regard to jurisdictional claims in published maps and institutional affiliations.

Ready to submit your research? Choose BMC and benefit from:

- fast, convenient online submission

- thorough peer review by experienced researchers in your field

- rapid publication on acceptance

- support for research data, including large and complex data types

- gold Open Access which fosters wider collaboration and increased citations

- maximum visibility for your research: over $100 \mathrm{M}$ website views per year

At $\mathrm{BMC}$, research is always in progress.

Learn more biomedcentral.com/submissions 